\title{
SURFACE TOPOGRAPHY AND ROUGHNESS PARAMETERS OF ELECTROSPARK COATINGS ON TITANIUM AND NICKEL ALLOYS
}

\author{
Original scientific paper
}

UDC: $620.198: 669.24 ' 295$

https://doi.org/10.18485/aeletters.2021.6.3.1

\author{
Georgi Kostadinov ${ }^{1}$, Pancho Danailov ${ }^{2}$, Rayna Dimitrova ${ }^{2}$, Mara Kandeva ${ }^{2,3}$, Todor Penyashki ${ }^{{ }^{*}}$, \\ Valentin Kamburov ${ }^{2}$, Antonio Nikolov ${ }^{2}$, Blagoj Elenov ${ }^{1}$ \\ ${ }^{1}$ Institute of Soil Science, Agrotechnologies and Plant Protection „N. Pushkarov“, Sofia, Bulgaria \\ ${ }^{2}$ Technical University of Sofia, Bulgaria \\ ${ }^{3}$ South Ural State University, 76 Prospekt Lenina, Chelyabinsk, Russia
}

\begin{abstract}
:
This paper examines the topography and roughness of coatings of hard alloyed materials deposited by electrospark deposition (ESD) on titanium and nickel alloys with different initial roughness. The influence of the electrode materials and the energy parameters of the ESD process on the roughness parameters $R a, R t, R q, R z, R m a x$, on the depth of waviness $W t$, the asymmetry $R s k$, the excess $R k u$, on the depth of core roughness $R k$ and the depth of the reduced picks roughness Rpk was established. The conditions for ESD are indicated, under which the traces of the previous treatment are erased and the characteristics of the initial substrate surface are improved. The numerical values of the roughness parameters for electrospark coatings from five types of hard alloys and one type of $\mathrm{TiB}_{2}$ based electrode with nanosized additives have been established.
\end{abstract}

\section{ARTICLE HISTORY}

Received: 17.06.2021.

Accepted: 17.08 .2021$.

Available: 30.09.2021.

\section{KEYWORDS}

Electrospark deposition, coatings, roughness, carbide materials, amorphous alloy

\section{INTRODUCTION}

The unique combination of high strength and corrosion resistance, low density, biocompatibility, etc. [1], of titanium and its alloys make them desirable materials for many industries. However, the wide application of these attractive materials is strictly limited by their low surface hardness and low wear resistance [2-4]. At present, the improvement of the surface properties of titanium alloys is carried out mainly by the methods of surface modification and application of wearresistant coatings [4,5]. Among these methods, the lightest, cheapest, most affordable and most versatile is electric spark deposition ESD [6-8]. The ESD surface layer changes the friction conditions in two main directions: a change of surface composition, the structure, and the surface microgeometry change. It is known that most often after ESD the roughness of the coatings is higher than that of the base and the relatively high roughness of ESD coatings adversely affects the wear resistance of coated products [6-25].

From the viewpoint of the tribology, the larger the shape and dimensions of the contact micro unevenness the smaller the actual area of contact between the friction bodies, and the wear is proportional to the volume of mutual penetration of the roughnesses. The friction " $T$ "as a force depends proportionally on the actual area of contact of the bodies - $T=\mu$.HB.Sr=k.Sr [10-12], where $T$-friction force; $\mu$ - coefficient of friction; $H B$ Brinell hardness; $\mathrm{Sr}$ - actual contact area. Therefore, taking into account the micro- unevenness in improving the tribological properties of the friction units is one of the key points for providing an improved friction regime and conditions.

However, there is insufficient research data for the study the roughness of ESD coatings and accordingly, for the relationship between the roughness and wear resistance of coated surfaces in the literature. Consequently, controlling coating 
roughness in ESD is an important and topical practical task and at the same time a task of scientific importance [10-14].

The aim of this study is to compare and evaluate the parameters of the roughness of the coatings and to determine the appropriate electrode materials and technological parameters of ESD with low energy pulses to obtain wear-resistant coatings of hard alloys based on WC, TiC, TiN, TiCN on titanium and nickel alloys with different initial roughness.

The study of the general regularities of the change in the qualitative characteristics of the coatings will allow identifying ways both to improve the quality of the coatings and to manage the process parameters, to create methodologies for control of ESD modes and to improve the tribological properties of the layered surfaces.

\section{MATERIALS AND METHODS}

In the present work the topography and the roughness parameters of the coatings of carbide materials deposited on titanium and nickel alloys with different initial roughness are studied. Most often, the micro-roughness of the treated surfaces is evaluated with the roughness parameter $R a$ or with the parameter $R z$ ( 5 points each). The other parameters of the height and step, which are related to the shape of the profile of the irregularities - parameters of asymmetry and sharpness of the profile, slope of the profile and reference length of the profile are used relatively rarely, but these parameters contain indirect information on the wear resistance of surfaces. Based on the friction processes and the conditions for contact plastic and elastic deformations and stress concentration, in the present work the following parameters have been selected, used to assess the influence of the applied coatings on the roughness:

-The change of the classic parameters $R a$ - the arithmetic mean of the absolute values of the deviations of the profile from the midline within the base length, $R q$ - geometric mean (rms) value of the deviations of the profile from the midline, $R t$ - the maximal height of the roughness of the profile - the distance between the line passed through the highest protrusion (peak) of the profile and the line passed through the lowest depression of the profile, $R z$ - the average of all Rti values over the length of the measurement, also known as Rtm (in DIN 4776 standard), Rpm - the mean value of the maximal values of the protrusions Rpi obtained for each reference length, $R y$ - the maximal of all $R t$ values for the estimated measurement length, and the maximum depth of the waviness profile $W t$, as a function of the pulse energy and the type of the electrode material, was studied.

The change of the parameters is also examined and evaluated:

- $R s$ - the average value of the distances between two adjacent peaks containing a peak (protrusion, peak) and a hollow (recess) of the profile.

- Rsm - the average distance between the peaks of the profile along the midline;

- Rpm - the average value of the obtained maximal values of the protrusions $R p i$ for each base length;

- Rsk - for asymmetry (distortion) of the distribution, which is a measure of the degree of

asymmetry of the distribution curve of the amplitudes of the profile around the midline;

- $R k u$ - for sharpness of the distribution, skewness and kurtosis of height distribution of surface, which is a measure of the shape of the distribution curve of the amplitudes of the profile.

- $R k$ - which conditionally estimates the volume of material contained in the core of the roughness on the values of which could be judged for the wear resistance of the layered surfaces;

- Rpk - height of the material at the tips of the roughness.

In order to obtain coatings with low roughness and fewer structural defects, low pulsed energy ESD equipment is used in the present work - "Carbide Hardedge" with the following parameters: Short circuit current - $0.2-1.5 \mathrm{~A}$, Voltage- $U=80 \mathrm{~V}$, oscillation frequency of the oscillator $-100 \mathrm{~Hz}$. The individual layering modes are numbered from 1 to 6 in the order of increase of pulse energy given in Table 1.

Table 1. Regimes for ESD whit vibrating electrode

\begin{tabular}{|c|c|c|c|c|c|c|}
\hline No of regimes, & $\mathbf{1}$ & $\mathbf{2}$ & $\mathbf{3}$ & $\mathbf{4}$ & $\mathbf{5}$ & $\mathbf{6}$ \\
\hline Capacitance, $\mu \mathrm{F}$ & 1.5 & 3.5 & 5 & 7 & 10 & 20 \\
\hline Pulse energy E.10-2, $\mathrm{J}$ & 0.5 & 1 & 1.6 & 2 & 3 & 7 \\
\hline
\end{tabular}

The coatings are deposited on titanium alloy Ti6Al4V and on invar Ni36Fe alloys with different initial roughness. Electrodes with designations and composition are used according to Table 2. 
The surface roughness parameters and of thickness $\delta, \mu \mathrm{m}$ of the resulting coatings are measured by using profilometers -"Surtronic $3+"$ Taylor-Hobson, TESA Rugosurf 10-10G, and AR132B at EN ISO 13565-2:1996, ISO 25178, DIN EN ISO 13565-1:1998-04, DIN EN ISO 13565-2:1998-04 and BDS (BDS - Bulgarian State Standard) ISO 4287 standards. Bilateral roughness measurement of the samples was performed in three sections in two mutually perpendicular directions for each of the sections. The results obtained are arithmetic mean after determination of standard deviation, and confidence interval. Sharply diverging values are rejected by the method of Grubbs. Excel software were used for data processing and illustration.

Table 2. Composition of used for ESD hardalloyed electrodes

\begin{tabular}{|l|l|}
\hline \multicolumn{1}{|c|}{$\begin{array}{c}\text { Type of ESD } \\
\text { electrode }\end{array}$} & \multicolumn{1}{|c|}{ Chemical composition } \\
\hline TN & $\mathrm{TiN}+14 \%(\mathrm{Ni}+\mathrm{Cr})+1 \%\left(\mathrm{Cu}-\mathrm{B}-\mathrm{Al}_{2} \mathrm{O}_{3}-\mathrm{C}\right) ;$ \\
\hline KNT16 & $\mathrm{TiCN}+26 \%(\mathrm{Ni}+\mathrm{Mo})$ \\
\hline TC-TN & $\begin{array}{l}\mathrm{TiC}+\mathrm{TiN}+14 \%(\mathrm{Cr}+\mathrm{Ni}+\mathrm{Mo})+1-2 \% \\
\left(\mathrm{Cu}-\mathrm{B}-\mathrm{Al}{ }_{2} \mathrm{O}_{3}+\mathrm{C}\right)\end{array}$ \\
\hline TiB2-TiAl & $74 \% \mathrm{Ti}+12 \% \mathrm{~B}+14 \% \mathrm{Al}[14,19,20]$ \\
\hline NWW10T10B10 & $\begin{array}{l}50 \% \mathrm{WC}+10 \% \mathrm{TiB} 2+10 \% \mathrm{~B}_{4} \mathrm{C}+(\mathrm{Ni}- \\
\mathrm{Cr}-\mathrm{B}-\mathrm{Si}-\mathrm{C})\end{array}$ \\
\hline NWW15B10T20 & $\begin{array}{l}55 \% \mathrm{WC}+20 \% \mathrm{TiB} 2+10 \% \mathrm{~B} 4 \mathrm{C}+(\mathrm{Ni}- \\
\mathrm{Cr}-\mathrm{B}-\mathrm{Si}-\mathrm{C})\end{array}$ \\
\hline KW10T10B10 & $\begin{array}{l}50 \% \mathrm{WC}+10 \% \mathrm{TiB} 2+10 \% \mathrm{~B}_{4} \mathrm{C}+(\mathrm{Co}- \\
\mathrm{Cr}-\mathrm{Ni}-\mathrm{B}-\mathrm{Si}-\mathrm{C})\end{array}$ \\
\hline Al-Si & $12 \% \mathrm{Si}+\mathrm{Al}$ \\
\hline
\end{tabular}

The morphology and topography of the ESD layers were examined with a scanning electron microscope SEM "EVO MA10 Carl Zeiss".

\section{RESULTS AND DISCUSSION}

Some preliminary information about the surface structure and tribological properties can be obtained based on the surface morphology. The general view of the SEM topography of the surface of the coatings deposited with the electrodes described in Table 2 is shown in Fig. 1 at different magnifications. The obtained coatings have high density, and repeatability of the quality characteristics. Theirs surface roughness is higher than those of the substrate, and significantly lower than those obtained by traditional methods with the vibrating electrodes with higher pulse energy $\mathrm{E} \geq 0.1$ J $[6-9,15-21]$.

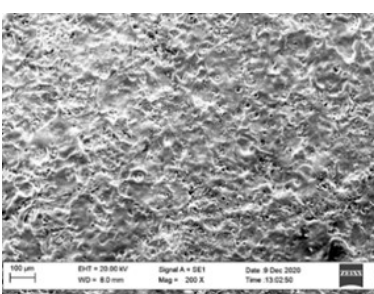

a) electrode KNT16, $E=0.03 \mathrm{~J}$

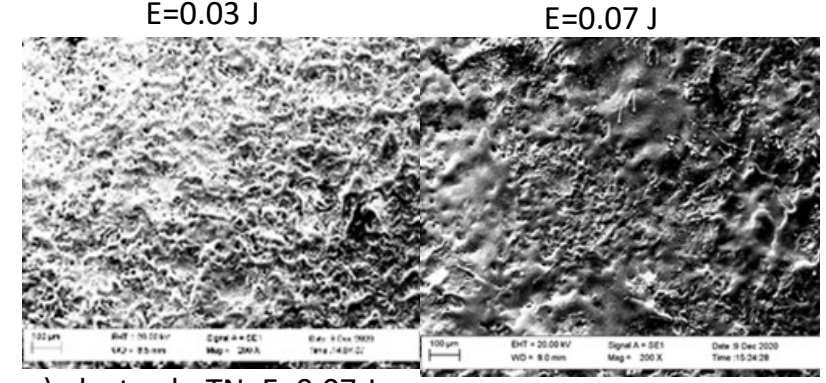

c) electrode $\mathrm{TN}, \mathrm{E}=0.07 \mathrm{~J}$

d) electrode KWB10T10, $\mathrm{E}=0.03 \mathrm{~J}$

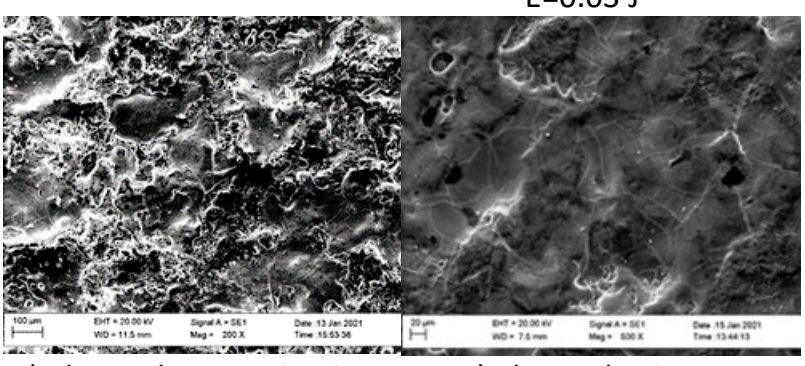

e) electrode KWB10T10, $\mathrm{E}=0.07 \mathrm{~J}$

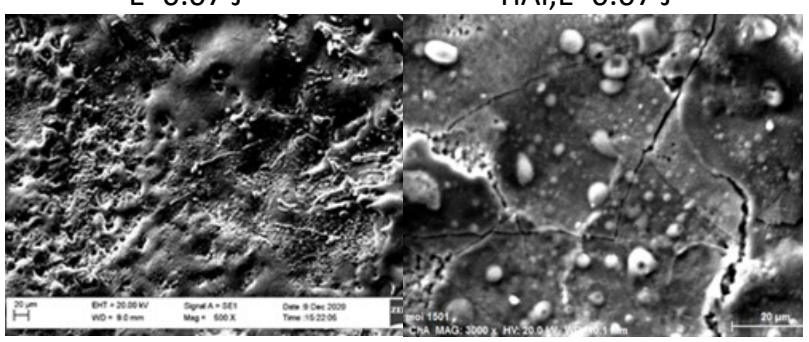

h) electrode KWB10T10, i) electrode Al-Si/Ti6Al4V, $E=0.03 \mathrm{~J}$

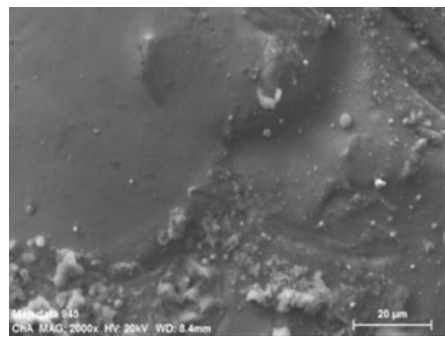

$\mathrm{E}=0.03 \mathrm{~J}$

j) electrode Al-Si/ invar- $E \approx 0.03 \mathrm{~J}$

Fig.1. General view of the SEM topography of coatings applied by vibration ESD on Ti6Al4V and invar alloys at different magnification

It is evident that the coatings form on surface of the titanium a heterogeneous structure with a specifical relief, formed with the participation mostly of a liquid phase. The liquid phase is present in the form of splashes and smoothed areas of the surface, formed as a result of the coalescence of individual drops (Fig.1 d, g and h). In this structure, 
the electroerosion craters and the smooth surface sections between them are distinguished. At higher magnification the presence of individual microcracks, pores and microscopic irregularities is also registered (Fig. $1 \mathrm{~g}$, $\mathrm{h}$ and i). The comparison of the surfaces obtained with different pulse energies (Fig.1 a, b, d, e and g) - (the latter at higher magnification), shows that the surface of the coatings obtained at the maximal for the apparatus energy $0.07 \mathrm{~J}$ (Fig. $1 \mathrm{~b}$ and g), is coarser and with more irregularities and protrusions than those with average energy $0.03 \mathrm{~J}$. The surfaces obtained with different electrodes at the same energy are similar, which is determined by the physical nature of the ESD process. Both the coatings of WC-based electrodes types $\mathrm{KW}$ and NW, and those of tungsten-free electrodes based on TiCN, TiN, TiC and $\mathrm{TiB}_{2}$ show certain individual features. The coatings of tungsten-free electrodes are more uniform and with a more homogeneous and finegrained structure than those obtained with the KW and NW type electrodes. At higher energy, however, separate protrusions and irregularities appear, resulting from the transfer of electrode material in a solid (not completely melted softened phase (Fig.1 b, c, e and g). The surface of Al-Si coatings is similar, but the presence of a network of microcracks is registered in the titanium substrate (Fig.1 i), the amount of which increases with increasing pulse energy, while in the invar substrate single, rare microcracks are observed in the coatings (Fig. $1 \mathrm{j}$ ).

It is noticed that in the coatings applied with pulse energy up to $0.03 \mathrm{~J}$ the number of microcracks and irregularities is less. At this energy the highest uniformity and smoothness is reported in the coatings of non-tungsten electrodes (Fig.1 a, b and c). The topography of the coatings of $\mathrm{TiB}_{2}-\mathrm{TiAl}$ electrodes is similar (Fig.1 g), but with an increase in energy above $0.03 \mathrm{~J}$ separate protrusions and irregularities appear, which deteriorate the uniformity and roughness of the layered surface. The surface of the coatings of "NW-" and "KW-" electrodes (Fig. $1 \mathrm{~d}$, e and $\mathrm{h}$ ) is rougher and uneven, but the thickness of these coatings is also higher and reaches 25 microns. The amount of the microcracks, irregularities and protrusion increases noticeably with an increase in pulse energy above 0.03J. At higher magnification (Fig. $1 \mathrm{i}$ and $\mathrm{j}$ ) in the coatings of non-tungsten electrodes a network of microcracks is observed, while in multicomponent tungsten containing electrodes only individual microcracks are registered. Moreover, an increase in the roughness of the coatings is observed with an increase in the pulse energy.

In Fig.2, 3 and 4 the change of the roughness parameters of the coatings obtained on substrates with different initial roughness with the investigated electrodes is given depending on the pulse energy and electrode materials.

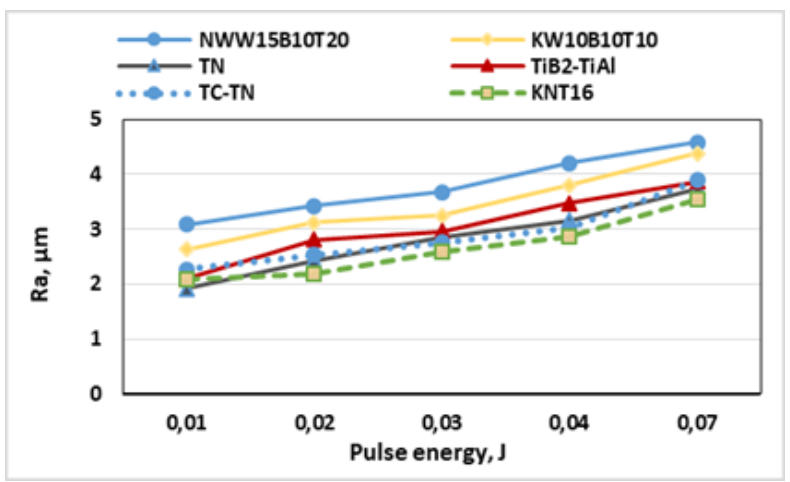

Fig.2. Roughness of the coatings on Ti6Al4V as a function of the energy of the pulses at initial roughness of the base $R a=2.5 \mu \mathrm{m}$

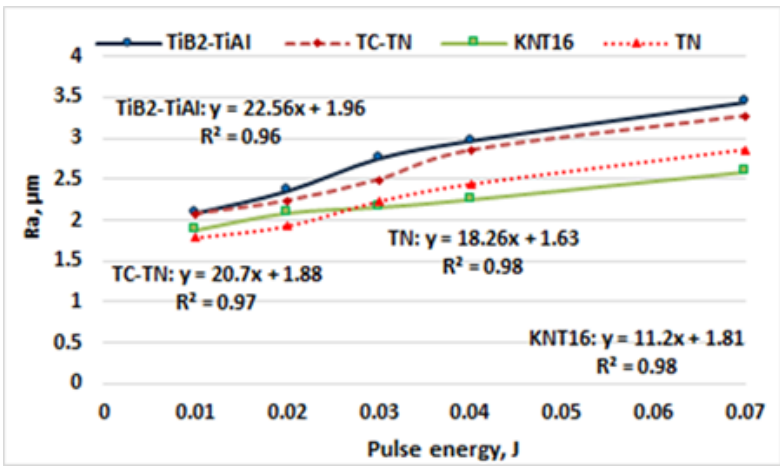

Fig.3. Roughness Ra of coatings vs. the pulse energy at initial roughness of the base $R a=1.67 \mu \mathrm{m}$

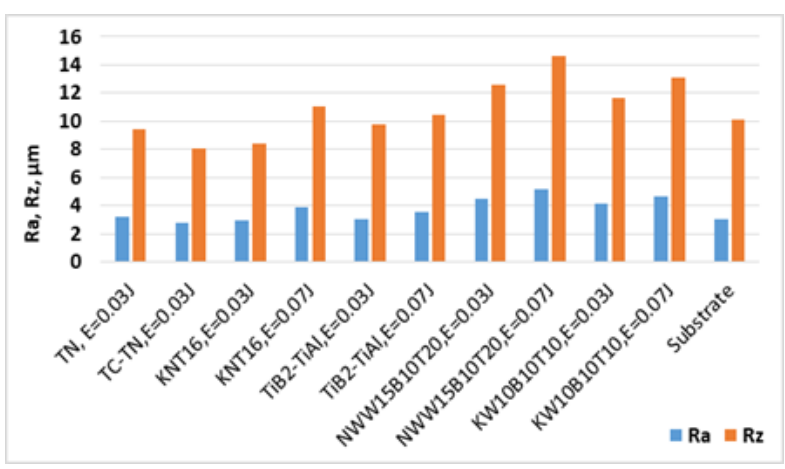

Fig.4. Roughness parameters $R a, R z$ of coatings vs two modes of the pulse energy at initial roughness of the base $R a=3.05 \mu \mathrm{m}$

Table 3 shows the values of the roughness parameter $R a$ and the thickness $b$ of the coatings obtained with the used electrodes at average and maximum pulse energy of the "Carbide Hardedge" device. 
In Table 4 the values of the studied roughness parameters of coatings obtained with the used electrodes at the average and maximal pulse energy for the "Carbide Hardedge" device onto substrates with an initial roughness $R a=0.2 \mu \mathrm{m}$ are given.

Table 3. Roughness $R a$, thickness $\delta$ of coatings on titanium alloy Ti6Al4V at initial roughness of the base $R a=1.67 \mu \mathrm{m}$

\begin{tabular}{|c|c|c|c|}
\hline Designation of electrodes & $E, J$ & $\mathrm{Ra},(\mu \mathrm{m})$ & $\delta,(\mu \mathrm{m})$ \\
\hline $\mathrm{TN}\left(\mathrm{TiN}+10 \% \mathrm{Ni}+\mathrm{Cr}+1 \%\left(\mathrm{Cu}-\mathrm{B}-\mathrm{Al}_{2} \mathrm{O}_{3}+\mathrm{C}\right)\right.$ & 0.03 & 2.3 & 11 \\
\hline $\mathrm{TN}\left(\mathrm{TiN}+10 \% \mathrm{Ni}+\mathrm{Cr}+1 \%\left(\mathrm{Cu}-\mathrm{B}-\mathrm{Al}_{2} \mathrm{O}_{3}+\mathrm{C}\right)\right.$ & 0.07 & 2.86 & 14 \\
\hline KNT16 (TiCN+26\%(Ni+Mo) & 0.03 & 2.16 & 16 \\
\hline KNT16 (TiCN+26\%(Ni+Mo) & 0.07 & 2.34 & 16 \\
\hline TC-TN (TiCTiN+14\%(Ni+Mo)+1-2\%(Cu-B- $\left.\mathrm{Al}_{2} \mathrm{O}_{3}+\mathrm{C}\right)$ & 0.03 & 2.39 & 10 \\
\hline TC-TN (TiCTiN+14\%(Ni+Mo)+1-2\%(Cu-B- $\left.\mathrm{Al}_{2} \mathrm{O}_{3}+\mathrm{C}\right)$ & 0.07 & 2.97 & 10 \\
\hline $\mathrm{TiB}_{2}-\mathrm{TiAl}$ & 0.03 & 2.8 & 11 \\
\hline $\mathrm{TiB}_{2}-\mathrm{TiAl}$ & 0.07 & 3.41 & 15 \\
\hline KW10B10T10 & 0.03 & 3.25 & 14 \\
\hline KW10B10T10 & 0.07 & 4.26 & 18 \\
\hline NWW15B10T20 & 0.03 & 3.12 & 16 \\
\hline NWW15B10T20 & 0.07 & 5.19 & 21 \\
\hline NWW10B10T10 & 0.03 & 3.49 & 17 \\
\hline NWW10B10T10 & 0.07 & 5.45 & 25 \\
\hline $\mathrm{Ti}_{6} \mathrm{Al}_{4} \mathrm{~V}$ (base) & - & 1.67 & - \\
\hline
\end{tabular}

Table 4. Surface parameters of ESD coatings at initial roughness of the base $R a=0.2 \mu \mathrm{m}$

\begin{tabular}{|c|c|c|c|c|c|c|c|c|c|c|}
\hline $\begin{array}{c}\text { Parameter } \\
\text { /Electrode/ } \\
\text { energy }\end{array}$ & $\begin{array}{c}\mathrm{TN} \\
0.03 \mathrm{~J}\end{array}$ & $\begin{array}{l}\text { KNT16 } \\
0.03 \mathrm{~J}\end{array}$ & $\begin{array}{l}\text { KNT16 } \\
0.07 \mathrm{~J}\end{array}$ & $\begin{array}{l}\text { TC-TN } \\
0.03 \mathrm{~J}\end{array}$ & $\begin{array}{c}\text { KW10B1 } \\
\text { 0T10 } \\
0.03 \mathrm{~J}\end{array}$ & $\begin{array}{c}\text { KW10B1 } \\
\text { 0T10 } \\
0.07 \mathrm{~J}\end{array}$ & $\begin{array}{c}\text { NWW10 } \\
\text { B10T10 } \\
\text { 0.07 J }\end{array}$ & $\begin{array}{c}\mathrm{TiB}_{2}-\mathrm{TiAl} \\
0.03 \mathrm{~J}\end{array}$ & $\begin{array}{c}\mathrm{TiB}_{2}-\mathrm{TiAl} \\
0.07 \mathrm{~J}\end{array}$ & $\mathrm{Ti}_{6} \mathrm{Al}_{4} \mathrm{~V}$ \\
\hline$R a, \mu m$ & 2.39 & 2.16 & 2.35 & 2.4 & 3.19 & 4.51 & 5.15 & 2.23 & 3.26 & 0.197 \\
\hline$R q, \mu m$ & 3.04 & 2.77 & 2.93 & 3.17 & 4.04 & 5.83 & 6.5 & 2.86 & 4.21 & 0.303 \\
\hline$R t, \mu m$ & 20.04 & 19.02 & 19.25 & 19.74 & 25.3 & 33.36 & 36 & 19.74 & 27.7 & 3.24 \\
\hline$R z, \mu m$ & 13.94 & 13.04 & 13.15 & 14.12 & 18.5 & 24.6 & 26.1 & 12.57 & 18.5 & 1.38 \\
\hline$R y, \mu m$ & 18.83 & 18.45 & 18.19 & 19.32 & 22.88 & 33.35 & 38.53 & 18.47 & 26.8 & 3.24 \\
\hline$R p m, \mu m$ & 7.17 & 6.13 & 5.9 & 6.83 & 8,7 & 14.7 & 12.5 & 5.84 & 7.16 & 0.638 \\
\hline$R s, \mu m$ & 34.36 & 40.54 & 30.14 & 31.65 & 54.1 & 52.6 & 55.3 & 49.4 & 35.83 & 26.5 \\
\hline Rsk & -0.11 & -0.21 & -0.26 & -0.23 & -0.12 & 0.76 & -0.22 & -0.2 & -0.73 & -0.91 \\
\hline$R k u$ & 3.56 & 3.67 & 3.56 & 3.345 & 3.26 & 3.72 & 2.96 & $3, .75$ & 4.25 & 9.25 \\
\hline$R k, \mu m$ & 8.22 & 6.86 & 7.46 & 8.15 & 9.69 & 14.5 & 16.7 & 7.2 & 9.9 & 0.545 \\
\hline$R p k, \mu m$ & 8.66 & 7.01 & 8.28 & 9.33 & 5.24 & 9.34 & 9.63 & 2.91 & 3.85 & 2.85 \\
\hline$W t$ & 8.66 & 7.38 & 9.53 & 8.31 & 9.98 & 15.5 & 13.73 & 10.42 & 16.83 & 3.13 \\
\hline
\end{tabular}

From the obtained results (Tables 3 and 4; Fig.24 ) it is established that with increasing pulse energy, the roughness parameters and thickness $\delta$ of the coatings increase monotonically, and their specific values under the same other conditions are different for different layering electrodes. There is a proportional relationship - with increase in thickness $\delta$ grows and roughness and vice versa (Table 3). The coatings of NW- and KW- type electrodes with a soldering mass based on nickel and cobalt show the highest values of the roughness parameters. The coatings of the tungsten-free electrodes TN, TC-TN and KNT16 show smaller roughness parameters. Moreover, the higher is the content of soldering materials in the composition of the layering electrode, the higher are the values of roughness of the obtained coatings, respectively, and we can expect that they have the greatest coefficients of friction. After ESD on surfaces with an initial roughness $R a=0.2,1.67,2.5$ and $3 \mu \mathrm{m}$ (Table 3 and 4; Fig.2, 3 and 4), all height and step roughness parameters significantly increase compared to the parameters of the original surface, but the $R a$ parameter increases to a lesser extent.

The results show that the coatings obtained with the non-tungsten electrodes at pulse energy up to $0.04 \mathrm{j}$ having values for $R a$ in the range of $1.8 \div 3 \mu \mathrm{m}$ can be used directly to increase the wear resistance of titanium alloys. The most promising in terms of roughness are the KNT16 and TN electrodes. The 
results show-that mainly the pulse energy and the type of electrode material determine the values of the parameters of the roughness of the coatings, and the influence of the initial roughness of the samples is less pronounced. ESD leads to a significant increase in all height parameters of the roughness compared to the initial values of the polished titanium surfaces, which is expected given the physical nature of the process.

With an increase in the pulse energy, an increase in the diameter and time of the spark discharge occurs, as a result of which the erosion of the electrodes increases. The depth and size of the craters of the solidified material on the cathode grows and, as a result, the roughness increases [6-9, 14-15]. In the ESD of the samples with initial roughness $R a=1.67,2.5$ and $3 \mu \mathrm{m}$, the roughness $R a$ of the coatings of all used electrodes at pulse energy up to $0.03 \mathrm{~J}$ is close to that of the initial titanium surface (Fig. 2, 3 and 4). At the pulse energy increases over $0.04 \mathrm{~J}$, the roughness $R a$ of the coatings significantly increases.
It is noteworthy, that in ESD on the samples with initial roughness $R a=2.5$ and $3 \mu \mathrm{m}$, the $R a$ parameters of coating roughness of all used electrodes at pulse energy up to $0.02 \mathrm{~J}$ are lower or commensurate with those of the initial titanium surface (Fig.2 and 4). With the increase of the pulse energy to $0.03 \mathrm{~J}$, the $R a$ parameters of the coatings from the non-tungsten and $\mathrm{KW}$ electrodes also increase, but $R a$ remains lower or near than those of the initial roughness $R a$. Therefore, ESD with these electrodes at a pulse energy of up to $0.03 \mathrm{~J}$ can be used to smooth the irregularities and traces of the previous treatment of the initial titanium surface, for example after additive technologies for the production of titanium parts or after the rough and semi-finished mechanical or electro erosion treatment of titanium surfaces.

Fig. 5 shows the profile of the roughness and the $R k$ parameter of uncoated and Fig. 6 - of coated samples with the studied electrodes.
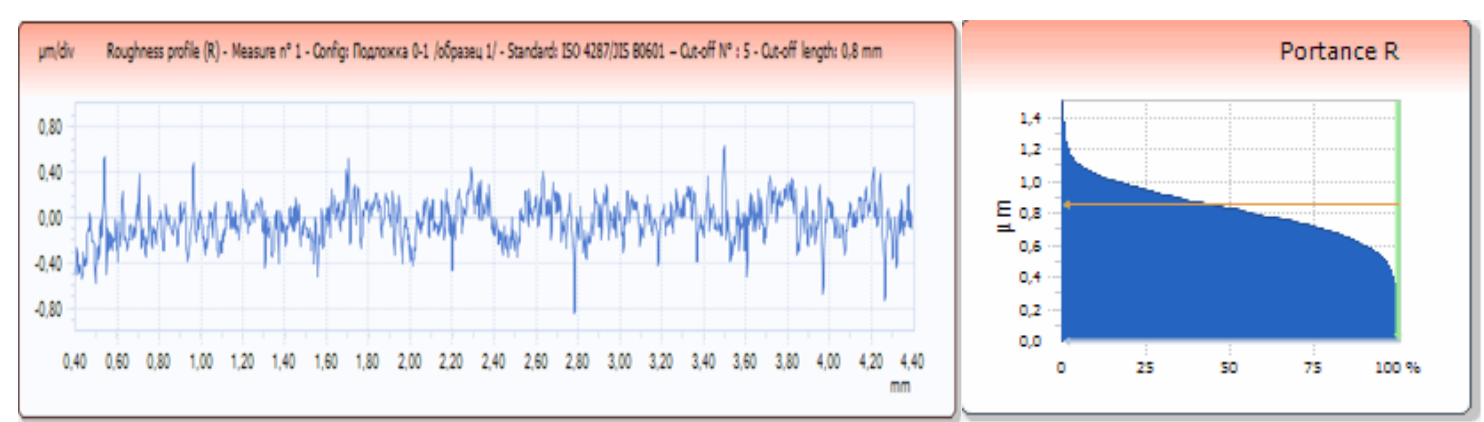

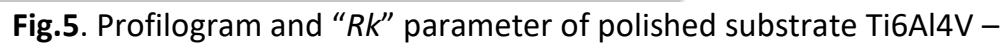
$R a=0.141 \mu \mathrm{m}, R z=1.137 \mu \mathrm{m}, R \max =1.35 \mu \mathrm{m}, R k=0.453 \mu \mathrm{m}, R p k=0.173 \mu \mathrm{m}$
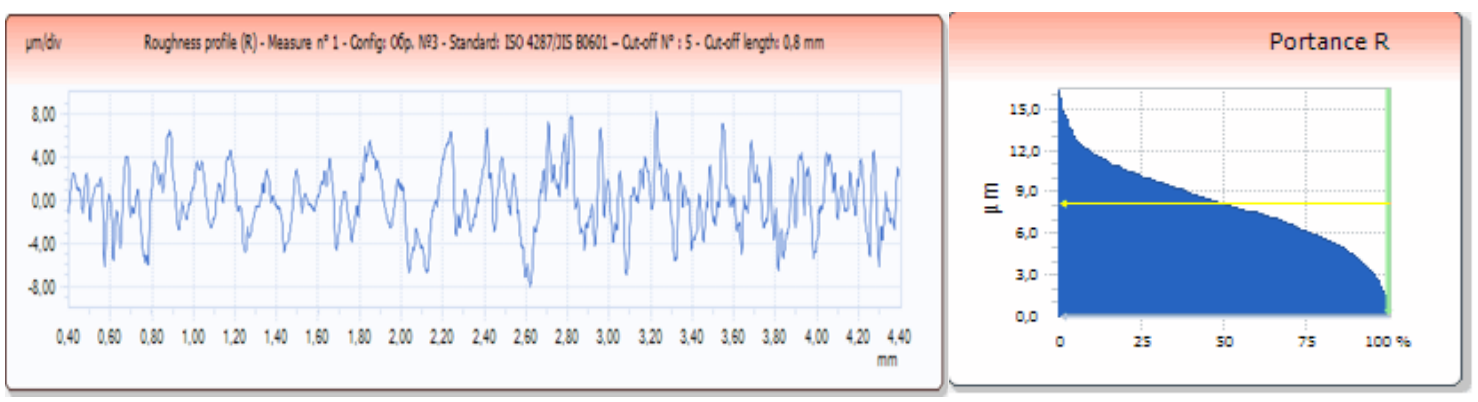

a) ESD with KNT16 electrode, $E=0.07 \mathrm{~J}$ :

$R a=2.33 \mu \mathrm{m}, R z=13.14 \mu \mathrm{m}, R \max =15.35 \mu \mathrm{m}, R k=7.39 \mu \mathrm{m}, R p k=2.57 \mu \mathrm{m}$
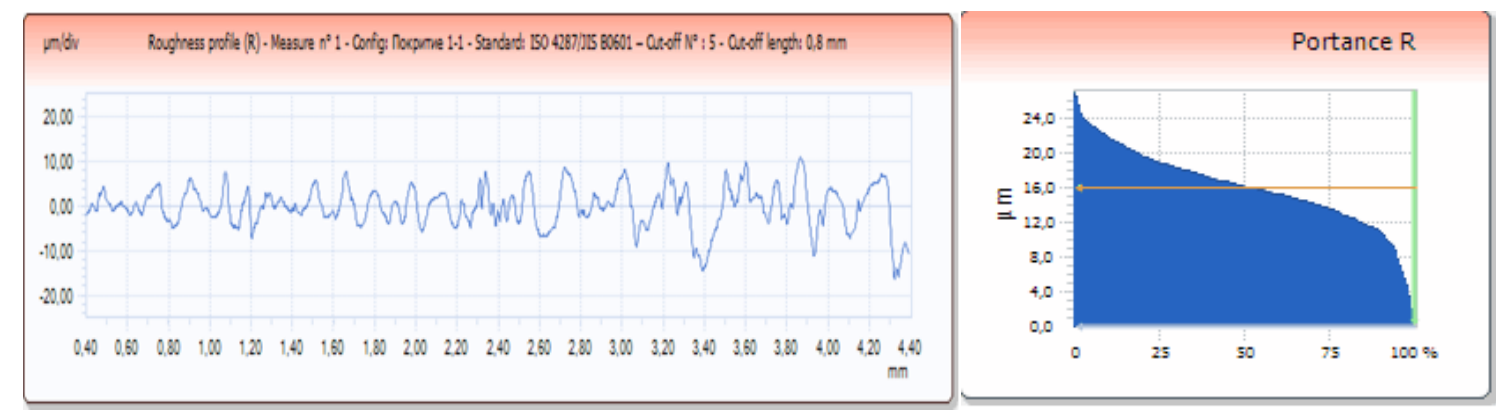

b) ESD with $\mathrm{TiB}_{2}-\mathrm{TiAl}$ electrode: $R a=3.45 \mu \mathrm{m}, R z=18.86 \mu \mathrm{m}, R \max =27 \mu \mathrm{m}, R k=9.79 \mu \mathrm{m}, R p k=3.57 \mu \mathrm{m}$ 


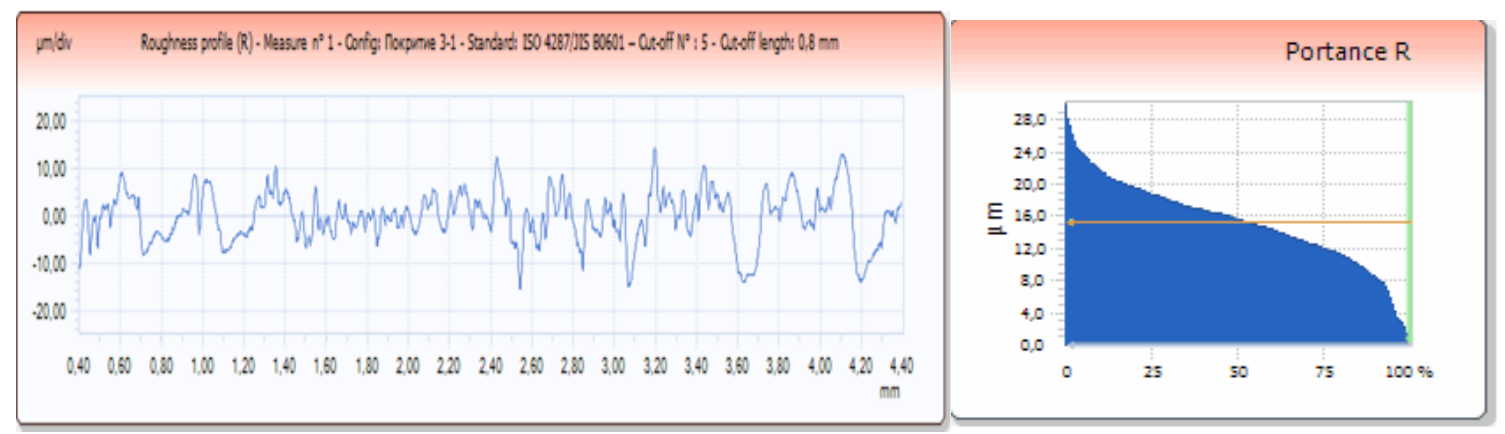

c) ESD with KW10B10T10: $R a=4.16 \mu \mathrm{m}, R z=24.25 \mu \mathrm{m}, R m a x=29.41 \mu \mathrm{m}, R k=8.58 \mu \mathrm{m}, R p k=4.45 \mu \mathrm{m}$

Fig.6. Profilograms and " $R k^{\prime}$ " parameter of coating from KNT16, TiB 2 -TiAl and KW10B10T10 electrodes on polished substrate Ti6Al4V at impulse energy $0.07 \mathrm{~J}$

From the figures and from Table 4 it is established that the influence of ESD on the other studied roughness parameters is diverse:

In ESD coatings, the asymmetry parameter Rsk decreases compared to that of the initial uncoated surfaces, as Rsk remains negative, which predetermines relatively good support properties of the layered surfaces.

The parameter $R k u$, which determines the sharpness of the shape of the roughness amplitude distribution, also decreases, compared to the same parameter at the initial surface: $R k u=9.25 \mu \mathrm{m}$, resp. $R k u=4.43 \mu \mathrm{m}$ (Table 4). For most of the coatings, the parameter $R k u$ has values close to the optimal $R k u \approx 3 \mu \mathrm{m}$, which is favorable under conditions of friction and wear of the layered surface, because most of the protrusions and depressions are concentrated around the middle line of the profile of the irregularities.

The parameter $R k$, (according to the international standard EN ISO 13565-2: 1996), which determines the depth of the core of the roughness and the wear of the surface in the area of the coating increases significantly compared to that of the base (Table 4). Higher $R k$ values can adversely affect wear resistance and reduce service life and lubrication retention index. The sum of the roughness parameters $R p k+R k$ (according to the international standard EN ISO 13565-2: 1996), which characterizes the wear of the surface in the coating area, increases compared to that of the uncoated surface, which can characterize the coating surface as less wear resistant in terms of roughness parameters. This potentially provides a smaller cycle and degree of wear in the stage of operation of two contact surfaces, according to the known Lorentz curve for the stages of wear of contact bodies - operation, uniform wear and catastrophic wear. The lowest values of this sum were reported for the coatings of tungsten-free electrodes applied at a pulse energy of less than $0.03 \mathrm{~J}$. With an increase in the energy to $0.07 \mathrm{~J}$, the sum $P k+P p k$ increases significantly, and in ESD with $\mathrm{KW}$ and NW type electrodes, its values reach a fivefold increase compared to that of the uncovered surface. In ESD, the maximal wave height $W t$ of the undulation is also increased compared to the initial uncoated surface, which is unfavorable in the case of surface contact because the actual contact areas are reduced and the contact pressure is increased.

Fig.7 shows photos of an invar surface after rough and semi-pure machining and after subsequent ESD with Al-Si electrodes. ESD manages to erase the traces of the previous mechanical treatment of the invar substrate. Despite the different initial roughness $R a$ of the substrate (Fig.7 $a$ and $b$ ), the roughness of the coatings applied under the same regime is approximately the same.
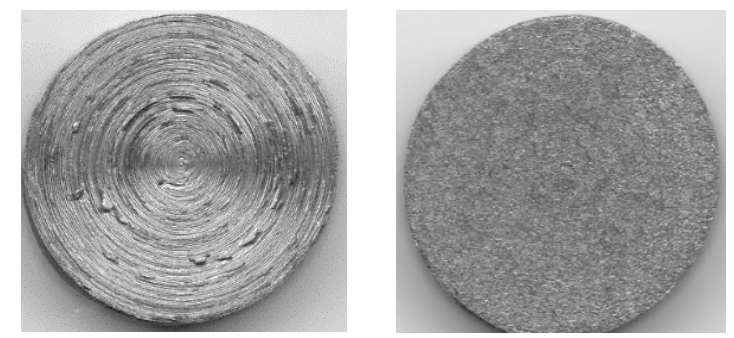

a) Al-Si/invar, $E=0.07 \mathrm{~J} R a$ initial $=6.66 \mu \mathrm{m}$, Coating $R a=4.32 \mu \mathrm{m}$
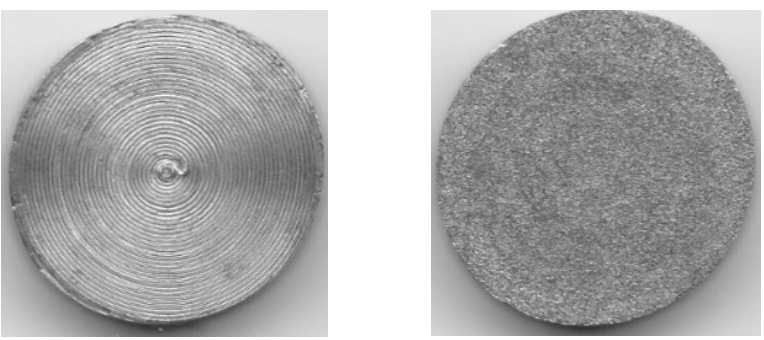

b) Al-Si/invar, $\mathrm{E} \approx 0.07 \mathrm{~J} R a$ initial $=4.25 \mu \mathrm{m}$, Coating $R a=4.3 \mu \mathrm{m}$

Fig.7. General appearance of Al12Si coatings on invar with different initial roughness 
The figure shows that at ESD the initial roughness of the samples decreases. This shows that ESD can be successfully used to reduce the initial roughness when it is higher than a certain value - in this case at $R a \geq 6-7 \mu \mathrm{m}$. After applying a coating to a surface with an initial roughness of $R a \geq 6 \mu \mathrm{m}$, all height and step parameters of roughness decrease on average 1.15 to 1.5 times compared with the roughness parameters of the initial surface. Therefore, ESD can also be used to reduce scattering and for leveling the relief of the original surfaces.

It is known [6-9,15-25] that the increase in energy leads to an increase in the thickness, hardness and amount of wear-resistant phases in the coatings, which creates prerequisites for increased wear resistance of the coated surfaces. At the same time, however, the roughness and unevenness of the coatings increases.

Up to certain limits, which are different for different specific cases, this increase is compensated by the high microhardness, the higher content of wear-resistant phases, the greater thickness and the fine-grained structure of the coatings $[8,15,17-19,21,25]$. After these limits, the higher roughness begins to adversely affect the layered surfaces' tribological properties and reduce the lamination effect.

In order to avoid this reduction and to improve and optimize the wear resistance of the coated surfaces, there is a need to reduce the surface roughness, which can be achieved in the following possible ways:

1. Use of low-energy pulses ( $E<0.05 \mathrm{~J})$, which will form coatings with lower roughness parameters, but also with lower thickness and not reaching the optimal possible wear resistance [8,15-21,25];

2. Using a higher pulse energy and applying an additional - upper (last layer) with low pulse energy, or with graphite electrodes [8,15,17,19,21-24]. However, this step can only reduce roughness to a certain extent, which in some cases with high surface quality requirements may be insufficient.

3. Use of high-energy pulses and subsequent processing of the obtained rough surface. Such treatments may be mechanical or ultrasonic surface plastic deformation, laser or plasma smoothing, abrasion, grinding and the like. In these cases, however, the thickness of the applied coatings will decrease and the optimally achieved wear resistance will not be optimally possible but will be closer to it.
The results of the literature $[6-9,15,17-18]$ show that despite the higher values of the roughness parameters, the coatings show higher wear resistance than the base. This is due to their finegrained structure and high hardness and wear resistance of roofing materials. However, based on the results obtained for the parameters of topography and roughness of ESD samples at pulse energy above $0.03 \mathrm{~J}$, however, additional processing of the layered surface - diamond or laser smoothing, ultrasonic or mechanical surface plastic deformation, rubbing, polishing, sanding, etc., can affect the height, pitch and the main structural parameters - Rsk, Rku and $R k$ and will be able improve the wear resistance of the layered surfaces.

The variety of possible practical cases requires the study of changes in coating roughness depending on the elements of ESD modes. In these cases, conducting preliminary experiments allows not only to examine the influence of process parameters on roughness but also to influence the object of study, actively participate in the research, and to manage and optimize processes.

\section{CONCLUSION}

The coatings of the multicomponent carbide tungsten electrodes type KW and NW, as well as those of tungsten-free alloys obtained at a pulse energy up to $0.03 \mathrm{~J}$ have values for $R a$ in the range $2.16 \div 3 \mu \mathrm{m}$ and can be used directly to increase the wear resistance of titanium and nickel alloys. At pulse energy above $0.03 \mathrm{~J}$ all the parameters of the height of the roughness increase $-R a, R q, R t, R p m$, $R z$ and $R y$ compared to the initial values. The step parameters $R s$ and $R s m$ are also increased. In order to improve the quality of the coatings formed by the ESD method at high pulse energy, it is necessary to use finishing operations (mechanical or ultrasonic surface plastic deformation, or diamond polishing, grinding, etc.).

The values of the roughness parameters of the coatings are determined mainly by the pulse energy and the type of electrode material, and the influence of the initial roughness of the samples is less pronounced.

On the basis of a comparative analysis, the conditions for ESD have been determined under which complete erasure of the traces from the previous treatment and improvement of the surface characteristics have been obtained, and which presuppose an increase in the wear 
resistance of the layered samples. The use of electrodes of low-melting alloys of aluminum (Al) with silicon- $\mathrm{Al}-\mathrm{Si}$ as a result of electrospark discharges make it easier to melt and penetrate from the melt in cathode surface and fill the scratches obtained after machining.

The obtained results, which show the relationship between the parameters of the ESD process and the roughness of the layered surface, allow the determination of the parameters of the ESD mode, in which coatings with predetermined roughness on titanium and nickel surfaces will be obtained. The established dependencies can be used to develop technologies to improve the surface characteristics and wear resistance of titanium and nickel alloys.

\section{ACKNOWLEDGMENTS}

The present work is based on researches that are funded from the Bulgarian National Science Fund of the Ministry of Education and Science under the bilateral project Bulgaria- Russia "Improving the Quality of Surfaces Obtained by Additive Technologies by Reactive Electro-spark Processing" and the project "Technological Features and Regularities of Creation of New High Wear Resistant Composite Coatings on Titanium Alloys by Electrical Spark Deposition Process".

\section{NOTE}

The abstract of this paper is published at the $10^{\text {th }}$ International Conference on Tribology BALKANTRIB ' 20 organised in Belgrade, on May 2022, 2021.

\section{REFERENCES}

[1] C. Leyens, M. Peters, Titanium and Titanium Alloys: Fundamentals and Applications. WileyVCH Verlag GmbH \& Co. KGaA, 2003. https://doi.org/10.1002/3527602119

[2] H. Dong, Tribological properties of titaniumbased alloys. Surface Engineering of Light Alloys, Woodhead Publishing Series in Metals and Surface Engineering, Cambridge, UK, 2010, 58-80.

[3] Z. Doni, M., Buciumeanu, L. Palaghian, Topographic and Electrochemical Ti6Al4V Alloy Surface Characterization in Dry and Wet Reciprocating Sliding. Tribology in Industry, 35 (3), 2013: 217-224.
[4] F. Živić, N. Grujović, S. Mitrović, D. Adamović, V. Petrović, A. Radovanović, S. Đurić, N. Palić, Friction and Adhesion in Porous Biomaterial Structure, Tribology in Industry, 38 (3), 2016: 361-370.

[5] H. Garbacz, P. Wiecinski, M. Ossowski, M.G. Ortore, T. Wierzcho'n, K.J. Kurzydłowski, Surface engineering techniques used for improving the mechanical and tribological properties of the mechanical and tribological properties of the Ti6A14V alloy. Surf. Coat. Technol., 202 (11), 2008: 2453-2457. https://doi.org/10.1016/i.surfcoat.2007.08.06 $\underline{8}$

[6] A.E. Gitlevich, V.V. Mikhaĭlov et al., Élektroiskrovoe legirovanie metallicheskikh poverkhnostel̆, Kishinev, Shtinitsa, 1985. (in Russian).

[7] V. Mikhailov, A. Gitlevich, A. Verkhoturov, A. Mikhaylyuk, A. Belyakovsky, L. Konevtsov, Electrospark alloying of titanium and its alloys, physical and technological aspects and the possibility of practical use. Short review, Electronic Processing of Materials, 49 (5), 2013: 21-44. (in Russian)

[8] G.D. Kostadinov, T.G. Penyashki, D.D. Radev, Mathematical Modeling of Roughness Changing of Hard Metal Coatings Obtained by Contactless Electrospark Deposition. Surf. Engin. Appl. Electrochem, 55, 2019: 522-530. https://doi.org/10.3103/S1068375519050077

[9] V. Mikhailov, E. Pasinkovsky, K. Bachu, P. Peretyatku, On the issue of electrospark alloying of titanium and its alloys. Electronic Processing of Materials, 42 (3) 2006: 106-111. (in Russian)

[10]M. Kandeva, The Contact Approach in Engineering Tribology, "Technical University Sofia", Sofia, 2012.

[11] A. Vencl, L. Ivanović, B. Stojanović, E. Zadorozhnaya, S. Miladinović, P. Svoboda, Surface Texturing for Tribological Applications: A Review. Proceedings on Engineering Sciences, 1 (1), 2019: 227-239. https://doi.org/10.24874/PES01.01.029

[12] A. Vencl, K. Jakimovska, B. Ivanova, J. Ruzic, S. Simeonov, M. Kandeva, Static and Kinetic Friction of Electroless Ni Composite Coatings. Journal of Achievements in Materials and Manufacturing Engineering, 70 (1), 2015: 1321. 
[13] M. Kandeva, D. Karastoyanov, G. Nikolcheva, B. Stojanović, P. Svoboda, A. Vencl, Tribological Studies on Copper-Based Friction Linings. Tribology in Industry, 39 (2), 2017: 228-237. https://doi.org/10.24874/ti.2017.39.02.10

[14] F. Svahn, Å. Kassman-Rudolphi, E. Wallén, The influence of surface roughness on friction and wear of machine element coatings. Wear, 254 (11), 2003: 1092-1098.

[15] E.A. Levashov, E.Zamulaeva, A.E. Kudryashov, P.V. Vakaev, M.I. Petrzhik, A. Sanz, Materials science and technological aspects of electrospark deposition of nanostructured WCCo coatings onto titanium substrates. Plasma Processes and Polymers, 4 (3) 2007: 293-300. https://doi.org/10.1002/ppap.200600148

[16] Yu.I. Mulin, A. Verkhoturov, V. Vlasenko, Electrospark alloying of surfaces of titanium alloys. Prospective Materials, (1), 2006: 79-85. (in Russian)

[17] V. N. Gadalov, R. Abashkin, Yu. Boldyrev, E. Balabaeva, A. Lytkin, Cutting-tool wear and hardening of high-speed steel by local electrospark coating application. Russian Engineering Research, 29 (4), 2009: 419-422. https://doi.org/10.3103/s1068798x09040200

[18] T. Penyashki, G. Nikolcheva, G. Kostadinov, M. Kandeva, Improving the tribological properties of cutting tools by contactless electrical spark deposition (LESD), $15^{\text {th }}$ International Conference on Tribology SERBIATRIB '17, May 17-19, 2017, pp.394-407.

[19] A. E. Kudryashov, Zh. Eremeeva, E. Levashov, V. Lopatin, A. Sevost'yanova, E. Zamulaeva, On Application of Carbon-Containing Electrode Materials in Technology of Electrospark Alloying: Part 1. Peculiarities of Coating Formation Using Electrospark Treatment of Titanium Alloy OT4-1. Surf. Engin. Appl. Electrochem., 54 (5), 2018: 437-445. https://doi.org/10.3103/S1068375518050083
[20] E.A. Levashov, P. Vakaev, E. Zamulaeva, A. Kudryashov, Yu. Pogozhev, D. Shtansky, A. Voevodin, A. Sanz, Nanoparticle dispersionstrengthened coatings and electrode materials for electrospark deposition. Thin Solid Films 515 (3), 2006: 1161-1165.

https://doi.org/10.1016/j.tsf.2006.07.140

[21] V. Gadalov, S. Safonov, E. Romanenko, Increase of wear resistance of the powder titanic alloy of TYU7M2F2TS2 by electrospark the alloying from PG-10N-01 alloy, Strengthening technologies and coatings, (12), 2013: 20-24. (in Russian)

[22] A.E. Kudryashov, Zh. Eremeeva, E. Zamulaeva, A. Strelets, E. Levashov, T. Sviridova, Influence of secondary electrospark treatment with carbon-containing materials on the properties of titanium alloys, Strengthening technologies and coatings (Упрочняющие технологии и покрытия), (5), 2010: 17-21. (in Russian)

[23] V. Panashenko, Composition, structure and properties of electrospark and laserelectrospark ZrB2-containing coatings on titanium alloys, Electrical contacts and electrodes. Ser.: Composite, layered and gradient materials and coatings, Institute for Problems in Materials Science (IPMS) is Ukrainian, 2014: 134-142. (in Russian)

[24] T. C. Bin, L. D. Xin, W. Zhan, G. Yang, ElectroSpark Alloying Using Graphite Electrode on Titanium Alloy Surface for Biomedical Applications, Appl. Surf. Sci., 257 (15), 2011: 6364-6371.

https://doi.org/10.1016/j.apsusc.2010.12.007

[25] T. Penyashki, G. Kostadinov, I. Mortev, E. Dimitrova, Improving the Surface Properties of Steel $210 c r 12$ by Non-Contact Electrical Spark Deposition with Electrodes Based of WC and TiC, Journal of the Balkan Tribological Association, 23 (1-I), 2017: 69-81. 